\title{
Routine Progesterone Supplementation in Threatened Abortion: Is It a Sound Practice?
}

\author{
Adel E. Elgergawy ${ }^{1 *}$, Ahmed E. Abdelnaby ${ }^{2}$, Shereen B. Elbohoty ${ }^{1}$ \\ ${ }^{1}$ Department of Obstetrics and Gynecology, Faculty of Medicine, Tanta University, Tanta, Egypt \\ ${ }^{2}$ Tanta University Hospitals, Tanta, Egypt \\ Email: ^dradelali775@gmail.com
}

How to cite this paper: Elgergawy, A.E. Abdelnaby, A.E. and Elbohoty, S.B. (2019) Routine Progesterone Supplementation in Threatened Abortion: Is It a Sound Practice? Open Journal of Obstetrics and $G y$ necology, 9, 1541-1548.

https://doi.org/10.4236/ojog.2019.912150

Received: November 5, 2019

Accepted: December 2, 2019

Published: December 5, 2019

Copyright (C) 2019 by author(s) and Scientific Research Publishing Inc. This work is licensed under the Creative Commons Attribution International License (CC BY 4.0).

http://creativecommons.org/licenses/by/4.0/

\begin{abstract}
Aim: To evaluate the benefits and hazards of routine progesterone supplementation in threatened abortion and whether it is a sound practice or not. Materials and Methods: This study was conducted at Obstetrics and Gynecology Department, Tanta University in the period from January 2018 to December 2018. Eligible patients $(n=190)$ were randomly allocated into 2 groups: study group who will receive progesterone supplementation (prog. group) and control group who will receive no treatment (place. group). Results: No significant differences were found between both groups regarding all demographic data and pregnancy characteristics. Abortions were higher in place. group 17 (23.94\%) than in prog. group $12(16.44 \%)$ with no significant difference $\mathrm{p}$ value $=0.263$. The incidence of preterm labour was also higher in the place. group 22 (30.99\%) in comparison to the prog. group 17 (23.29\%) with no significant difference $p$ value $=0.300$. Conclusion: Progesterone supplementation in threatened abortion was not beneficial although it reduced abortion and preterm labour rates.
\end{abstract}

\section{Keywords}

Progesterone, Threatened Abortion, Supplementation, Sound Practice

\section{Introduction}

Spontaneous abortion occurs in about $15 \%$ to $20 \%$ of pregnancies. Threatened abortion occurs before 20 weeks' gestation with most of cases presenting by vaginal bleeding, with or without abdominal pain, while the cervix is closed and fetus is alive [1].

Threatened abortion is a common problem occurring in pregnancy, which either ends in inevitable abortion or pregnancy continues to maturity. This de- 
pends on early diagnosis and good therapeutic management. Many obstetricians worldwide are convinced that progesterone preparations either natural or synthetic treat threatened abortion without strong evidence supporting their use [2] [3].

Progesterone is the hormone that prepares the endometrium for implantation of zygote and exerts quiescent effect on uterine contractions. Progestogens are medications that are similar to progesterone in action. Progestogens play important role in threatened abortion as they reduce the miscarriage rate in women with past history of threatened abortion [4] [5].

A Cochrane Review (2011) evaluated whether progestogens supplementation in cases with threatened abortion reduced miscarriage or not. They also evaluated the safety of these medications for both fetus and mother. They compared patients receiving progestogens to placebo or no treatment. They found that treatment of abortion with progestogens compared to placebo reduced the risk of abortion to $0.47 \%$ while no difference regarding preterm labour. They were uncertain about the relation of progestogen to congenital anomalies as the quality of evidence was low [6].

Studies published in this point were found conflicting so we have conducted this study in order to evaluate whether progesterone supplementation in threatened abortion is a sound practice or not.

\section{Patients and Methods}

Study design and settings: This study was double-armed, double blinded, randomized controlled study. It was conducted at Obstetrics and Gynecology department, Tanta University Hospitals, Egypt in the period from 1st of January 2018 to 31th of December 2018. The ethical review board of Tanta Faculty of Medicine approved the study. Women who met the selection criteria of the study were invited to participate after signing an informed consent.

Patients: We included in our study women with threatened abortion diagnosed by history and ultrasound examination, singleton, viable fetus, gestational age $<20$ weeks, with closed normal length cervix. However; we excluded from our study women with short cervix $<2 \mathrm{~cm}$, carrying twins, with dead fetus and open cervix $\geq 2 \mathrm{~cm}$, history of cervical surgery or who refused to participate.

Sample size calculation: Sample size was calculated by using online program (Epi Info 7). Assuming $\mathrm{H} 1$ that progesterone supplementation is effective than placebo and $\mathrm{H} 0$ is that progesterone supplementation is ineffective. The confidence interval was 5 and confidence level was $95 \%$ with $50 \%$ percentage. The populations were total admissions with threatened abortion at Tanta University hospitals per year taken from local hospital registries which was nearly 500 . The estimated sample was 217 .

Randomization and allocation: Recruited patients were 217 and after selection 190 were eligible. The eligible cases randomly allocated into 2 groups; study group who will receive progesterone supplementation (Prog. group) and control 
group who will receive no treatment (place. group). Randomization was done by a computer generated random tables and every patient was given a numbered closed opaque envelopes with equal allocation 1:1 ratio. All patients and obstetricians were blinded to the allocation to avoid bias.

Intervention: Patients in the prog. group received rectal progesterone suppositories $400 \mathrm{mg}$ once daily while patients in the place. group received placebo suppositories rectally once daily. All suppositories were without names as managed by the third author. The duration of treatment was three weeks even if symptoms stopped. All cases were followed till delivery.

Study outcomes: Primary outcomes include relief of symptoms and completion of pregnancy beyond 20 weeks. Secondary outcome included abortion less than 20 weeks.

Ethical approval and study registration: This study was approved by local ethical committee of Tanta University before the start of recruitment on December 2017 with the following code No. 33108. The trial was registered on clinical trials.gov with the following ID: NCT03930212.

Statistical analysis: Data were analyzed by SPSS (SPSS Inc., Chicago, version 22). Quantitative data were presented in terms of mean \pm SD then compared using a Student's t-test. Qualitative variables were presented as frequency and percentage. Chi-square test was used for comparison between groups. For analysis, $\mathrm{p}<0.05$ was considered to be significant.

\section{Results}

Recruitment included 217 cases and after eligibility criteria 17 cases were excluded while 10 cases declined to participate. The eligible patients $(n=190)$ were allocated into either prog. group $(n=95)$ or place. group $(n=95)$. The flow of cases during study is illustrated in Figure 1.

There were no significant differences in demographic characteristics of enrolled patients regarding age, parity, occupation, residence or body mass index. Also gestational age at first visit, cervical length and diameters and clinical presentations were non-significantly different in both groups. These data were shown in Table 1.

The follow up results were shown in Table 2. The number of abortions was higher in place. group 17 (23.94\%) in comparison to prog. group $12(16.44 \%)$ with no significant difference $\mathrm{p}$ value $=0.263$. The incidence of preterm labour is also higher in the place. group 22 (30.99\%) in comparison to the prog. group 17 (23.29\%) with no significant difference $\mathrm{p}$ value $=0.300$. There were no differences regarding incidence of placental abruption, fetal demise, intrauterine growth restriction (IUGR) or premature rupture of membranes (PROM) with $\mathrm{p}$ value of $0.964,0.983,0.603$, and 0.556 respectively. No recorded cases of fetal anomalies and neonatal morbidity and mortality were comparable.

\section{Discussion}

The current study was designed to evaluate whether progesterone supplementation 


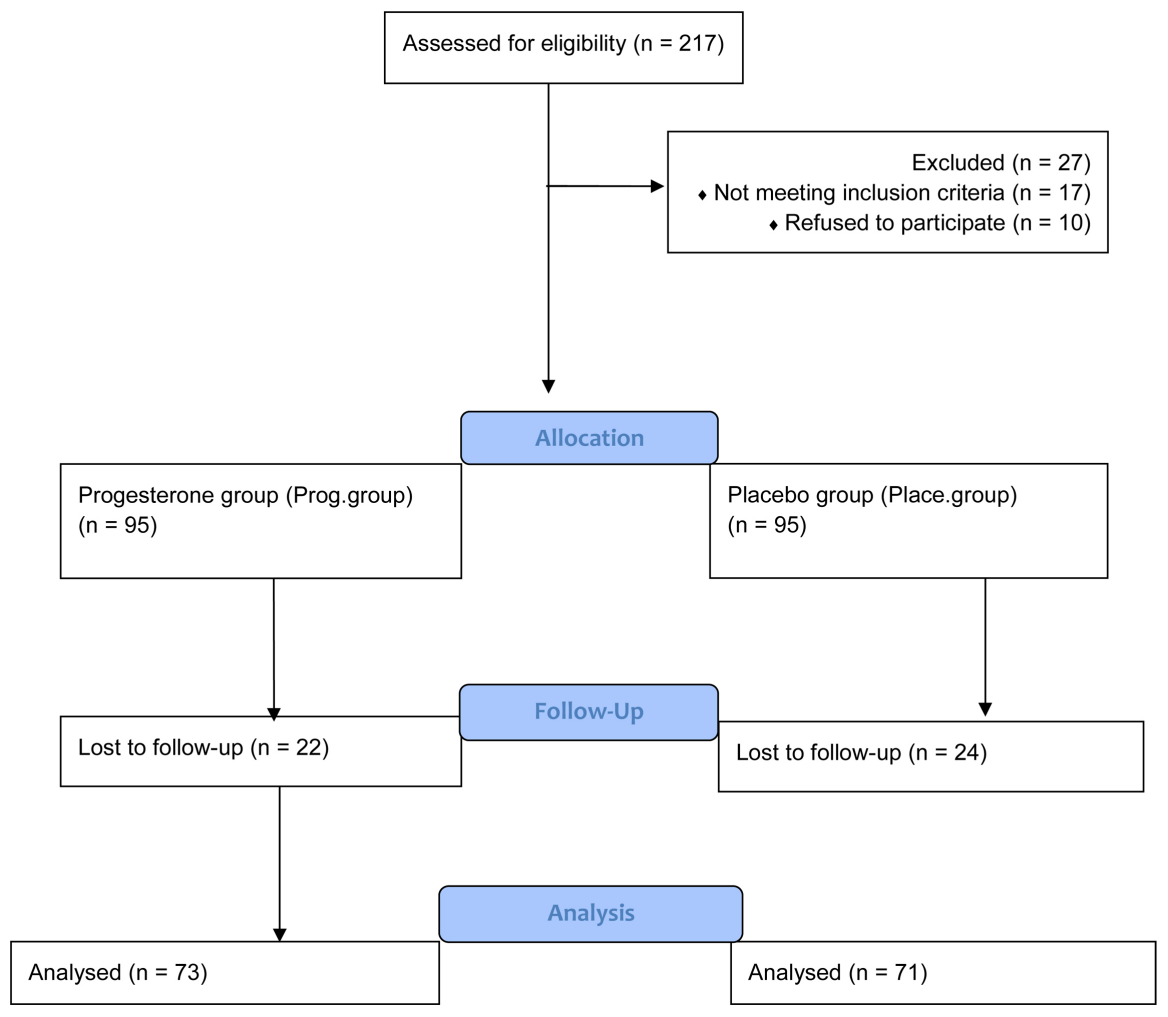

Figure 1. CONSORT flow chart of included patients and management options.

to patients with threatened abortion is a sound practice or not. The study assessed the efficacy and safety of rectal progesterone on abortion rate and occurrence of any anomalies.

In the current study, we found that abortion rate was lower in progesterone group $12(16.44 \%)$ in comparison to $17(23.94 \%)$ in placebo group with no significant difference $\mathrm{p}$ value $=0.263$ as shown in Table 2 . This finding doesn't support the random use of progestogenic drugs as there was no significant difference in both groups. Recent studies on threatened abortion showed that progesterone reduces pregnancy loss but with no solid evidence [7] [8] [9].

Progesterone prolongs pregnancy and decrease abortion rate by reducing pro-inflammatory cytokines and has an inhibitory effect on immune system. Moreover, progestogens reduce prostaglandins and consequently relax the smooth muscule of uterus. These effects inhibit myometrial hyper contractility and hence reduce both early and late pregnancy loss. This may encourage many obstetricians to adopt routine supplementation of progesterone to all patients with threatened abortion and for extended periods [10] [11].

El-Zibdeh and Yousef (2009), assessed the abortion rates in threatened abortion. They found that significant reduction of abortion rate in the group treated with dydrogesterone compared to the untreated group [12]. In the current study, most of the patients presented with vaginal bleeding alone in both prog. group and place. group with no statistically significant difference as shown in Table 1.

Ahmed et al. (2012) conducted a retrospective case-controlled study on 89 
Table 1. Demographic characteristics of enrolled patients.

\begin{tabular}{|c|c|c|c|c|}
\hline & $\begin{array}{l}\text { Study group } \\
\text { "Prog. group" } \\
(\mathrm{n}=73)\end{array}$ & $\begin{array}{l}\text { Control group } \\
\text { "Place. group" } \\
(\mathrm{n}=71)\end{array}$ & T. test & p-value \\
\hline \multicolumn{5}{|l|}{ Age (years) } \\
\hline$($ mean $\pm S D)$ & $24.45 \pm 4.58$ & $25.28 \pm 4.30$ & 0.944 & 0.347 \\
\hline Gravidity (mean $\pm \mathrm{SD}$ ) & $4.25 \pm 1.35$ & $4.32 \pm 1.42$ & 0.255 & 0.799 \\
\hline Parity $($ mean $\pm S D)$ & $2.01 \pm 1.24$ & $2.08 \pm 1.41$ & 0.266 & 0.790 \\
\hline \multicolumn{5}{|c|}{ Mode of previous delivery $(n, \%)$} \\
\hline Vaginal & $28(38.36 \%)$ & $26(36.62 \%)$ & 0.046 & 0.829 \\
\hline Cesarean & $45(61.64 \%)$ & $45(63.38 \%)$ & & \\
\hline \multicolumn{5}{|l|}{ Occupation $(n, \%)$} \\
\hline Occupied & $30(41.10 \%)$ & $29(40.85 \%)$ & 0.001 & 0.975 \\
\hline Non-occupied & $43(58.90 \%)$ & $42(59.15 \%)$ & & \\
\hline \multicolumn{5}{|l|}{ Residence (n,\%) } \\
\hline Rural & $44(60.27 \%)$ & $40(56.34 \%)$ & 0.227 & 0.633 \\
\hline Urban & $29(39.73 \%)$ & $31(43.66 \%)$ & & \\
\hline $\begin{array}{l}\text { BMI } \\
\left(\text { mean } \pm S D ~ k g / \mathrm{m}^{2}\right)\end{array}$ & $21.3 \pm 2.23$ & $21.7 \pm 2.11$ & 0.931 & 0.354 \\
\hline $\begin{array}{l}\text { Gestational age at first visit } \\
(\text { weeks })(\text { mean } \pm S D)\end{array}$ & $12.13 \pm 1.10$ & $11.95 \pm 1.30$ & -0.753 & 0.452 \\
\hline $\begin{array}{l}\text { Cervical length }(\mathrm{cm}) \\
(\text { mean } \pm \mathrm{SD})\end{array}$ & $3.9 \pm .0 .7$ & $4.2 \pm 0.93$ & 1.835 & 0.069 \\
\hline \multicolumn{4}{|l|}{ Cervical diameter (mm) } & 0.072 \\
\hline \multicolumn{5}{|l|}{ Main presentation $(\mathrm{n}, \%)$} \\
\hline Pain + bleeding & $27(36.99 \%)$ & $29(40.85 \%)$ & 0.224 & 0.635 \\
\hline Bleeding alone & $46(63.01 \%)$ & $42(59.15 \%)$ & & \\
\hline
\end{tabular}

BMI: Body mass index.

Table 2. Follow up results of enrolled patients.

\begin{tabular}{ccccc}
\hline & $\begin{array}{c}\text { Study group } \\
\text { "Prog. group" } \\
(\mathrm{n}=73)\end{array}$ & $\begin{array}{c}\text { Control group } \\
\text { "Place. group" } \\
(\mathrm{n}=71)\end{array}$ & Chi. square & p-value \\
\hline Abortion (n,\%) & $12(16.44 \%)$ & $17(23.94 \%)$ & 1.250 & 0.263 \\
Preterm labour (n,\%) & $17(23.29 \%)$ & $22(30.99 \%)$ & 1.073 & 0.300 \\
Full term delivery (n,\%) & $44(60.27 \%)$ & $32(45.07 \%)$ & 3.313 & 0.068 \\
Abruptio placentae (n,\%) & $5(6.85 \%)$ & $5(7.04 \%)$ & 0.002 & 0.964 \\
IUFD (n,\%) & $1(1.37 \%)$ & $1(1.41 \%)$ & 0.000 & 0.983 \\
IUGR (n,\%) & $11(15.07 \%)$ & $13(18.31 \%)$ & 0.270 & 0.603 \\
PROM (n,\%) & $7(9.59 \%)$ & $9(12.68 \%)$ & 0.345 & 0.556 \\
Fetal anomalies (n,\%) & Nil & Nil & - & - \\
Neonatal morbidity (n,\%) & $11(15.07 \%)$ & $15(21.13 \%)$ & 0.887 & 0.346 \\
Neonatal mortality (n,\%) & $3(4.11 \%)$ & $7(9.86 \%)$ & 1.829 & 0.176 \\
\hline
\end{tabular}

IUFD: Intrauterine fetal death; IUGR: Intrauterine growth restriction; PROM: Premature rupture of membranes. 
patients with threatened abortion. They found that threatened abortion was linked to increased incidence of poor outcomes. The related risks were premature rupture of the membranes, preterm delivery and reduced birth weight [13].

Cochrane systematic review (2011) stated that treatment of threatened abortion with progestogens compared to placebo reduced the risk of abortion to $0.47 \%$ while no difference regarding preterm labour [6]. Similarly, Lee et al. (2017) in their mata-analysis stated that the incidence of abortion was significantly reduced in the progesterone group than in the control group (13.0\% versus $21.7 \%$ ) [14]. On the other hand, Duan et al. (2010) in their study compared intramuscular progesterone to no treatment in threatened abortion. They found no difference regarding gestational age at delivery preterm labour rate [7]. This was also demonstrated by the current study where the incidence of preterm was $23.29 \%$ compared to $30.99 \%$ in prog. group and place. group respectively with $\mathrm{p}$-value $=0.300$. Regarding full term deliveries, there was no significant difference between both groups with p-value of 0.068 .

Another meta-analysis conducted by Dante et al. (2013) including 15 randomized controlled study to assess the effects of progesterone in threatened abortion. Their results show no statistically significant difference between patients receiving progestagens compared to placebo [15]. Also Akhtar et al. (2012) concluded in their study that the use of progesterone in management of threatened abortion improves pregnancy outcome to some extent but not significantly [16].

Coomarasamy et al. (2015), conducted a randomized clinical trial (PROMISE) (progesterone in miscarriage treatment) trial. They conducted the study in 45 hospitals in the UK and the Netherlands to evaluate whether progesterone is effective for prevention of recurrent miscarriage. They concluded that progesterone supplementations in early pregnancy did not increase live births in women with history of recurrent miscarriages [17].

\section{Conclusion}

In conclusion, the current study demonstrated that progesterone supplementation in threatened abortion is not a sound practice. It reduces abortion rates but with no significant difference between study and control group. Many studies were conducted in this issue and results were conflicting even systematic reviews and meta-analyses. It was found to be safe with no reported anomalies or side effects.

\section{Limitations}

Limitations of the study: Small sample size was the only limitation.

\section{Conflicts of Interest}

No conflicts of interests do exist for any author.

\section{References}

[1] Alimohamadi, S., Javadian, P., Gharedaghi, M.H., Javadian, N., Alinia, H., Khazardoust, S., Borna, S. and Hantoushzadeh, S. (2013) Progesterone and Threatened 
Abortion: A Randomized Clinical Trial on Endocervical Cytokine Concentrations. Journal of Reproductive Immunology, 98, 52-60. https://doi.org/10.1016/j.jri.2013.01.004

[2] Yassaee, F., Shekarriz-Foumani, R., Afsari, S. and Fallahian, M. (2014) The Effect of Progesterone Suppositories on Threatened Abortion: A Randomized Clinical Trial. Journal of Reproduction \& Infertility, 15, 147.

[3] Bradbury, J.T., Braun, W.E. and Gray, L.A. (2013) Maintenance of the Corpus Luteum and Physiologic Actions of Progesterone. In: Recent Progress in Hormone Research, Academic Press, Cambridge, 151-196.

[4] Hudić, I., Szekeres-Bartho, J., Fatušić, Z., Stray-Pedersen, B., Dizdarević-Hudić, L., Latifagić, A., Hotić, N., Kamerić, L. and Mandžić, A. (2011) Dydrogesterone Supplementation in Women with Threatened Preterm Delivery-The Impact on Cytokine Profile, Hormone Profile, and Progesterone-Induced Blocking Factor. Journal of Reproductive Immunology, 92, 103-107. https://doi.org/10.1016/j.jri.2011.08.006

[5] Di Renzo, G.C., Giardina, I., Clerici, G., Mattei, A., Alajmi, A.H. and Gerli, S. (2012) The Role of Progesterone in Maternal and Fetal Medicine. Gynecological Endocrinology, 28, 925-932. https://doi.org/10.3109/09513590.2012.730576

[6] Wahabi, H.A., Fayed, A.A., Esmaeil, S.A. and Bahkali, K. (2018) Progestogen for Treating Threatened Miscarriage. Cochrane Database of Systematic Reviews, No. 8, CD005943. https://doi.org/10.1002/14651858.CD005943.pub5

[7] Duan, L., Yan, D., Zeng, W., Yang, X. and Wei, Q. (2010) Effect of Progesterone Treatment Due to Threatened Abortion in Early Pregnancy for Obstetric and Perinatal Outcomes. Early Human Development, 86, 41-43.

https://doi.org/10.1016/j.earlhumdev.2009.12.007

[8] Qureshi, N.S. (2009) Treatment Options for Threatened Miscarriage. Maturitas, 65, S35-S41. https://doi.org/10.1016/j.maturitas.2009.10.010

[9] Weiss, J.L., Malone, F.D., Vidaver, J., Ball, R.H., Nyberg, D.A., Comstock, C.H., et al. (2004) Threatened Abortion: A Risk Factor for Poor Pregnancy Outcome, a Population-Based Screening Study. American Journal of Obstetrics \& Gynecology, 190, 745-750. https://doi.org/10.1016/j.ajog.2003.09.023

[10] Saccone, G., Schoen, C., Franasiak, J.M., Scott Jr., R.T. and Berghella, V. (2017) Supplementation with Progestogens in the First Trimester of Pregnancy to Prevent Miscarriage in Women with Unexplained Recurrent Miscarriage: A Systematic Review and Meta-Analysis of Randomized, Controlled Trials. Fertility and Sterility, 107, 430-438. https://doi.org/10.1016/j.fertnstert.2016.10.031

[11] Ayub, M., Ibrahim, A.K., Kausar, A. and Fahad, M. (2015) Effective Role of Progesterone with Proven Evidence in Threatened Abortion at Public Healthcare Sectors. The Journal of Medical Research, 1, 115-117.

[12] El-Zibdeh, M.Y. and Yousef, L.T. (2009) Dydrogesterone Support in Threatened Miscarriage. Maturitas, 65, S43-S46. https://doi.org/10.1016/j.maturitas.2009.11.013

[13] Ahmed, S.R., El-Sammani, M.-K., Al-Sheeha, M.A., Aitallah, A.S., Jabin Khan, F. and Ahmed, S.R. (2012) Pregnancy Outcome in Women with Threatened Miscarriage: A Year Study. Materia Socio Medica, 24, 26-28. https://doi.org/10.5455/msm.2012.24.26-28

[14] Lee, H.G., Park, T.C., Kim, J.H., Norwitz, E. and Lee, B. (2017) The Influence of Oral Dydrogesterone and Vaginal Progesterone on Threatened Abortion: A Systematic Review and Meta-Analysis. BioMed Research International, 2017, Article ID: 3616875. https://doi.org/10.1155/2017/3616875

[15] Dante, G., Vaccaro, V. and Facchinetti, F. (2013) Use of Progestagens during Early 
Pregnancy. Facts, Views and Vision in Obstetrics and Gynaecology, 5, 66.

[16] Akhtar, M., Fatima, N. and Jabeen, S. (2012) Role of Progesterone in the Management of Threatened Miscarriage. Cell, 346, Article ID: 8823343.

[17] Coomarasamy, A., Williams, H., Truchanowicz, E., Seed, P.T., Small, R., Quenby, S., Gupta, P., Dawood, F., Koot, Y.E., Bender Atik, R. and Bloemenkamp, K.W. (2015) A Randomized Trial of Progesterone in Women with Recurrent Miscarriages. New England Journal of Medicine, 373, 2141-2148.

https://doi.org/10.1056/NEJMoa1504927 